\title{
Orthopaedic Surgery
}

\section{Pattern and Outcome of Femoral Fractures Treated in a Regional Trauma Centre in South South, Nigeria}

\author{
Ibeanusi SE ${ }^{1^{*}}$ and J Chioma ${ }^{2}$ \\ ${ }^{1}$ Department of Surgery, University of Port Harcourt, Nigeria \\ ${ }^{2}$ Department of Surgery, Federal Medical Centre Umuahia, Nigeria
}

*Corresponding author: Dr. Sydney E IBEANUSI, Department of Surgery, University of Port Harcourt Teaching Hospital Port Harcourt, Nigeria, Tel: +234-805-1155884

\begin{abstract}
Introduction: The size, structure, and role of the femur make it a major load bearing bone in the body. Fractures of the femur present with varied patterns in aetiology, treatment modality and outcome. Fracture of the femur usually follows significant trauma which often can be lifethreatening particularly in young persons. Even in the elderly, the consequence of fractured femur can be lifethreatening.
\end{abstract}

Aim: This study aims to evaluate the pattern of presentation of fractures of the femur treated in a regional trauma centre in South South, Nigeria.

Patients and method: Prospectively collected data of patients presenting with fractured femur at the regional trauma centre from 1st January 2006 to $31^{\text {st }}$ December 2011 was retrospectively evaluated, looking at patterns of presentation, treatment given and outcome. Descriptive statistics were generated and presented from the observed results and inferences drawn where necessary.

Results: One thousand three hundred and thirty-four cases of fractured femur were treated at the centre during the period constituting about $10.9 \%$ of the fractures treated. All age groups were affected with significant majority of cases seen in the age group (21 to 30 ) years ( $n=411,30.8 \%$ ) following road traffic crashes $(970,72.7 \%) p<0.0001$. Ground level fall was the commonest cause $(38,2.8 \%)$ in elderly persons particularly females $(23,1.7 \%)$. Most of the fractures were closed $(\{1040,78 \%\} P<0.00001)$, involving the shaft of the femur $(775,56.1 \%)$. The proximal and distal femur were equally not spared $(n=330 ; 16.5 \%, n=339$; $25.4 \%$ ) respectively.

Majority of the patients particularly adults were treated by operative methods including open reduction and internal fixation with intramedullary nails $(629,47.2 \%)$, plates and screws $(206,15.4 \%)$, and K-wires $(18,1.3 \%)$, external fixation $(176,13.2 \%)$ and amputations $(n=5,0.4 \%)$. Non- operative treatments included casting with Plaster of Paris $(136,10.2 \%)$ and Traction $(135,10.1 \%)$. Majority of the fractures $(1113,83.7 \%)$ had attained significant union at six months post-injury to allow for a return of significant function (COST Score $70 \%$ and above) in $1035(77.1 \%)$ of cases. Seventy-two $(5.4 \%)$ cases of post-treatment infection were recorded with the infection rates highest in the open fractures grade IIIA $(n=30 / 10,27.5 \%)$ to grade IIIC $(n=4 / 8$, $50 \%)$.

Conclusion: Fractures of the femur have varied presentation. High energy injuries mainly from road traffic crashes was a significant contributor. Whatever treatment option adopted, application of sound principles and established guidelines produces acceptable results even the face of limited resources.

\section{Keywords}

Fractures of Femur, Presentation, Treatment, Outcome, Port Harcourt, Nigeria

\section{Introduction}

The femur is the longest, strongest and heaviest tubular bone in the human body and one of the principal load bearing bones in the lower extremity [1]. Extensive force/energy is required to break the femur; except if the bone has been weakened by other conditions as in pathological fracture $[2,3]$.

The pattern of presentation of femoral fractures varies with age of the patient, cause, and severity of the injury, and the location of the fracture on the femur $[4,5]$. In young persons, fractures of the femur are generally caused by high-energy forces and are often associated with multisystem injury. However, in the

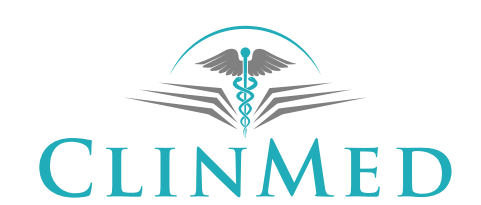

INTERNATIONAL LIBRARY

Citation: Ibeanusi SE, Chioma J (2019) Pattern and Outcome of Femoral Fractures Treated in a Regional Trauma Centre in South South, Nigeria. Int Arch Orthop Surg 2:006.

Accepted: February 26, 2019; Published: February 28, 2019

Copyright: (C) 2019 Ibeanusi SE, et al. This is an open-access article distributed under the terms of the Creative Commons Attribution License, which permits unrestricted use, distribution, and reproduction in any medium, provided the original author and source are credited. 
elderly population, femur fractures are typically caused by a low energy mechanism such as ground level falls especially fractures of the proximal and the distal femur $[6,7]$. Road traffic crashes (RTC) remain a principal cause of fracture of the femur in most series [8-10]. Other high energy injuries such as gunshot wounds, falls from heights, assaults and injuries from high-speed sports are other causes of fracture of the femur especially in young adults [10-12].

Complications and injuries associated with femoral fractures especially in the adult can be life-threatening and may include haemorrhage, internal organ injury, wound infection, fat embolism, and adult respiratory distress syndrome $[6,13,14]$. Therefore, treatment of femoral fractures should be prompt and appropriate otherwise such fractures can cause prolonged morbidity and extensive disability [14] such as prolonged hospitalisation, infections, inappropriate fracture unions such as delayed union, malunion, non-union and implant failure $[15,16]$.

Treatment methods for femoral fractures like those of other fractures have evolved over time ranging from the use of wooden splints in ancient civilizations to fabrics encased with wax [17], to use of metallic implants in varying shapes and approach to fixing the fractured femur. A better understanding of the fracture dynamics, improvement in types and quality of fracture fixations implants, better knowledge and skills of surgical fixation of fractures have all resulted to a better outcome. Whereas most fractures of the femur especially in adults are now treated surgically with the goal to allow mobilization of the patient and the injured limb as soon as possible [18], in children, non-operative options are often the preferred option [18]. In resource scares regions, non-operative treatment of femoral fractures such as casting with plaster of Paris (POP) and traction are also adopted even in adults with variable outcome because of none availability of skill, implants, and resources for operative treatments [19-21].

The timing of definitive treatment of femoral fracture remains subject of continuing debate. Previously delayed operative fixation of femoral fractures was the preferred option but by the 1980s, the standard care of major fracture was early fixation within 24-48 hours from injury or admission [22,23] with the development of the concept of "damage control orthopaedics" $[24,25]$. The focus for such unstable patients remains on control of haemorrhage, management of associated soft-tissue injury, and achievement of provisional fracture stability [26].

This study, therefore, aims to evaluate the epidemiology, treatments, and outcome of fractures of the femur treated in a dedicated trauma centre in Nigeria and possibly make recommendations based on the observations.

\section{Method}

Following Ethical approval according to Helsinki Declaration 1975 and revised in 2000 from the authority of International Centre for Advanced Medical Care and Development (ICAMCAD) the developers of the Registry, data of subsets of patients that presented with fractures of femur at a regional trauma centre in Port Harcourt Nigeria from $1^{\text {st }}$ January 2006 to $31^{\text {st }}$ December 2011 was retrospectively analysed. Since there was no direct interaction with the patients, informed consent from the patients was waived. However, the authors maintained the confidentiality of the patients' information throughout the study.

Information relating to age, gender, the cause of injury, location, type of fracture, fracture geometry type of treatment received, and outcome of treatment were analysed. Other variables assessed included postoperative complications; lengths of hospitalisation and duration to return to full function characterised by fracture union evidenced clinically by the absence of pain at fracture site, good radiological union and return to pre-injury activities. Since the trauma centre was jointly run with an international non-for profit, nongovernmental organisation, treatment of all patients at the centre was free of charge to the patient. Therefore, the cost of care did not influence the choice of treatment for the fracture but was influenced by the hospital policy at any time based on the available resources (material and skill) for a specific type of treatment at any specific time. For example, before the availability of implants, instruments, and optimisation of the operating room required for internal fixation in 2007, most of the fractures were treated by non-operative methods. The operative method adopted then was by external fixation for most open fractures and in some cases for closed fracture as a salvage procedure for inappropriate healing of closed fractures treated by non-operative methods.

Following treatment, the outcome was assessed for healing of associated soft tissue wounds, fracture union, duration of hospital stay, complications of treatment such as post-treatment infection, inappropriate fracture union (including delayed union, mal-union and non-union), implant failure, and functional status at 12 weeks; 24 weeks post definitive treatment using the Chesterly Outcome Score for Trauma (COST) [27].

Obtained data were analysed using statistical package for Windows version 20 (IBM SPSS Statistics for Windows, Version 20.0. IBM Corp. Amok, NY). Descriptive statistics were generated and presented as considered appropriate and inferential statistics provided when necessary. Categorical variables were presented as proportions and percentages and numerical variables presented as means and standard deviation (SD), and median with inter-quartile ranges (IQR) as considered appropriate. Chi-Square $\chi^{2}$ was used to test for observed 
differences among categorical variables. $\mathrm{P}$ values less than 0.05 are accepted as statistically significant.

\section{Results}

The total number of patients received in the facility during the period under review was 83040 with various types and severity of injuries. Of this lot, 12255 patients had extremity injuries of which 1334 cases were fractures of the femur $10.9 \%$. Nine hundred and sixtyseven $(72.5 \%)$ of the cases were seen in male patients whereas 366 cases $(27.5 \%)$ were in females given a male to female ratio of $2.6: 1$.

The age distribution of the fractures shows that most of the fractures ( $n=411,30.8 \%$ ) occurred in persons between the age group (21-30) years for both males and females. The age groups from 21 years to 50 years

Table 1: Age Distribution of fractures.

\begin{tabular}{|c|c|c|c|c|c|c|}
\hline Age in years & (Nos of cases) Males & $\%$ & (Nos of cases) Females & $\%$ & Total cases & $\%$ \\
\hline$\leq 10$ & 154 & 11.5 & 68 & 5.1 & 222 & 16.6 \\
\hline $11-20$ & 136 & 10.2 & 50 & 3.7 & 186 & 13.9 \\
\hline $21-30$ & 323 & 24.2 & 88 & 6.6 & 411 & 30.8 \\
\hline $31-40$ & 225 & 16.9 & 49 & 3.7 & 274 & 20.5 \\
\hline $41-50$ & 73 & 5.5 & 51 & 3.8 & 124 & 9.3 \\
\hline $51-60$ & 30 & 2.2 & 25 & 1.9 & 55 & 4.1 \\
\hline$\geq 60$ & 26 & 1.9 & 36 & 2.7 & 62 & 4.6 \\
\hline Total & 967 & 72.5 & 367 & 27.5 & 1334 & 100.0 \\
\hline
\end{tabular}

$\chi^{2}=113.618 ; P<0.0001$.

Table 2: Cause of Injury.

\begin{tabular}{|c|c|c|c|c|c|c|}
\hline Cause & Frequency & $\%$ & Males & $\%$ & Females & $\%$ \\
\hline Road traffic Crash & 970 & 72.7 & 698 & 52.3 & 272 & 20.4 \\
\hline Motor vehicle crash & 650 & 48.7 & 465 & 34.8 & 185 & 13.9 \\
\hline Motorcycle crash & 299 & 22.4 & 224 & 16.8 & 75 & 5.6 \\
\hline Non-Motorised crash & 21 & 1.6 & 9 & 0.7 & 12 & 0.9 \\
\hline Gunshot wounds & 236 & 17.7 & 177 & 13.3 & 59 & 4.4 \\
\hline Falls & 87 & 6.5 & 49 & 3.7 & 38 & 2.8 \\
\hline Falls from height & 49 & 3.7 & 34 & 2.5 & 15 & 1.1 \\
\hline Ground level falls & 38 & 2.8 & 15 & 1.1 & 23 & 1.7 \\
\hline Assaults & 41 & 3.1 & 37 & 2.8 & 4 & 0.3 \\
\hline Total & 1334 & 100.0 & 967 & 72.5 & 367 & 27.5 \\
\hline
\end{tabular}

$\chi^{2}=1676.287 . ; \mathbf{P}<0.00001$.

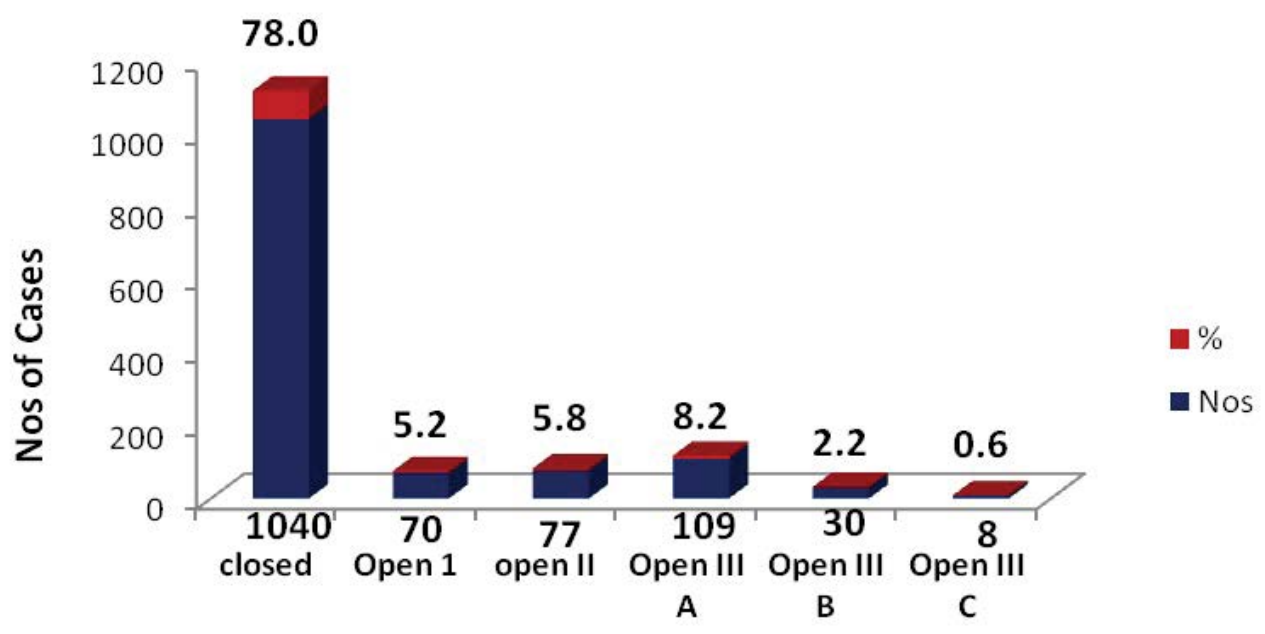

Type of fracture

Figure 1: Types of Fracture.

$\chi^{2}=2806.929, \mathrm{P}<0.00001$. 
contributed about $60 \%$ of the fractures. Children less than ten years contributed $16.6 \%$ (222) of the fractures while persons older than 60 years particularly females contributed $62(4.6 \%)$ of the fractures (Table 1$)$.

Table 2 showed that majority of the fractures $(n=$ $970,72.7 \%$ ) resulted from road traffic crashes of which most are from motor vehicular crashes ( $n=650,48.7 \%)$. Other causes were gunshot injuries $(n=236,17.7 \%$, and falls $(n=87,6.5 \%)$.

Majority of the fractures were closed ( $n=1040$, $78 \%$ ), while 294 of the fractures (22\%) were open fractures with Gustilo-Andersons grade III A open fracture [28] contributing 109 (8.2\%) of the cases while grade III C open fractures were $8(0.6 \%), \mathrm{P}<0.0001$ (Figure 1 ). The classification of the associated soft tissue wounds using Altemeier contamination classification method [29] showed that most of the fractures were closed as such clean. One hundred and thirty-one of the wounds (approximately $10 \%$ ) were contaminated on arrival while 26 of the injuries (2\%) were outrightly infected with the presence of pus on arrival Figure 2.
Table 3 showed that most of the fractures involved the shaft of the femur $(n=775,58.1 \%)$. The proximal femur and the distal femur contributed 220 (16.5\%) and $339(25.4 \%)$ respectively. There was no major difference in the distribution of the fractures between the right and the left sides (653 vs. 681 ), $P=0.44$.

The distribution of the fracture geometry showed that majority of the fractures were of the transverse and short oblique type ( $n=1018,76.3 \%)$ while 209 (15.7\%) of the fractures were comminuted in configuration Figure 3.

Table 4 showed that 853 (64.2\%) of the fractures were treated by internal fixation particularly by intramedullary nailing ( $n=629,47.2 \%), 176(13.2 \%)$ of the fractures were treated by external fixation, 136 cases were treated by casting while 5 cases were treated by amputation.

Most of the patients $(459,34.4 \%)$ were hospitalised between 2 to 6 weeks with the majority of patients ( $\mathrm{n}$ $=1174,88 \%$ ) spending less than 6 weeks on admission while 30 patients $(2.2 \%)$ spent more than 12 weeks on

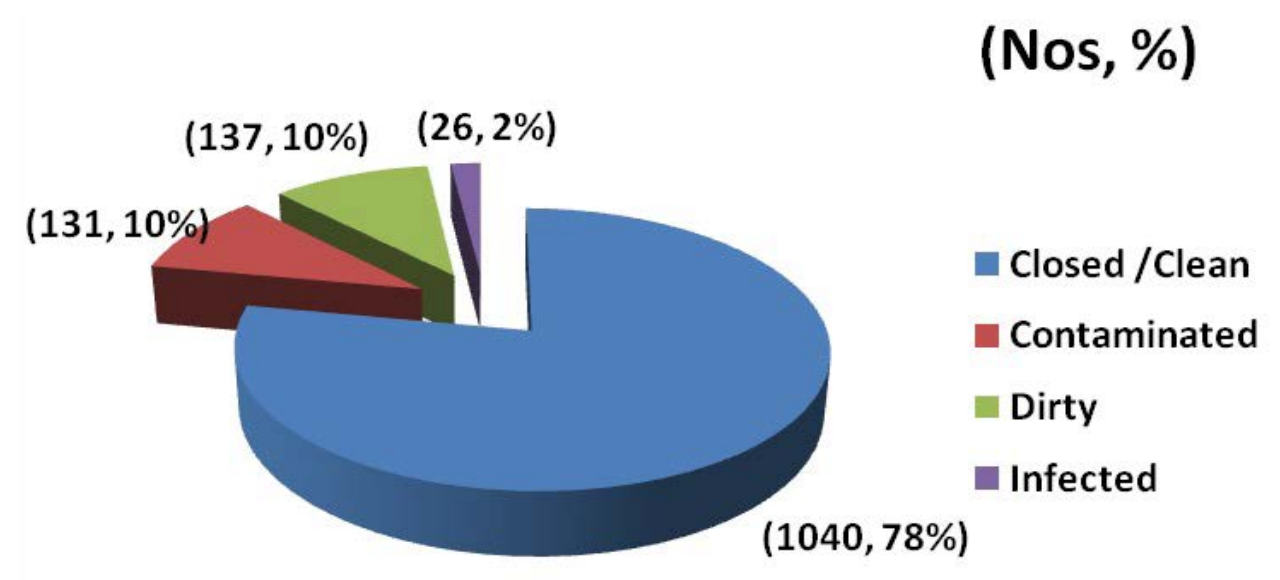

Figure 2: Classification of Associated soft tissue wounds (Altemeier contamination classification). $\chi^{2}=2012.246, \mathrm{P}<0.00001$.

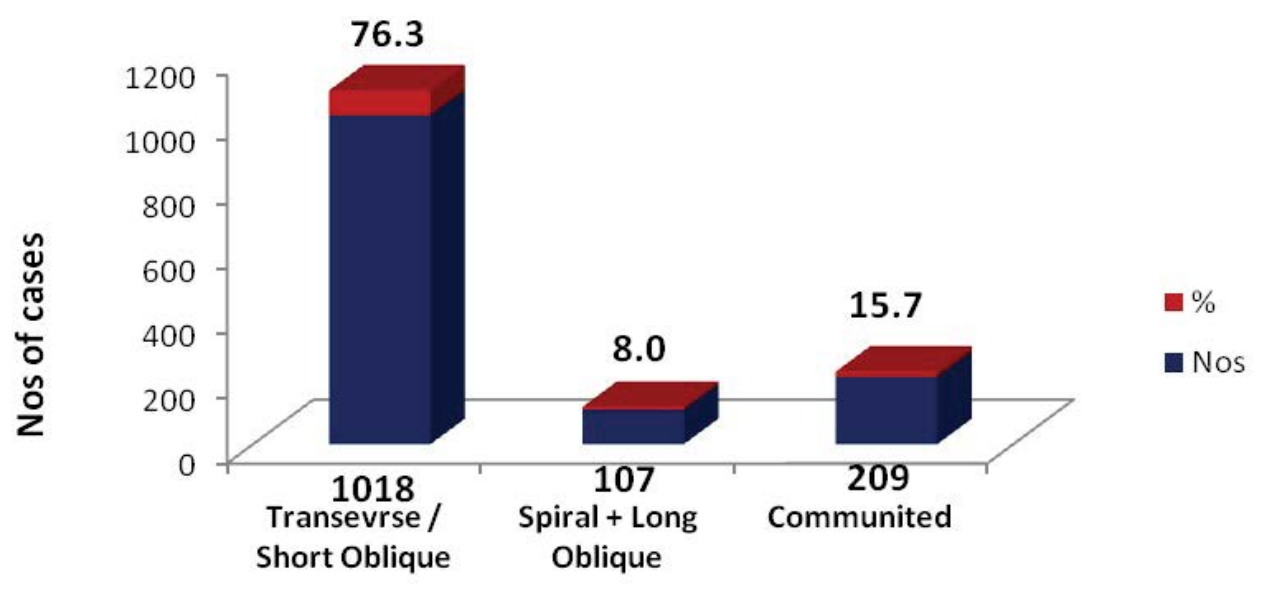

Geometry of fractures

Figure 3: Distribution of Geometry of Fractures.

$\chi^{2}=1118.189, \mathrm{P}<0.00001$. 


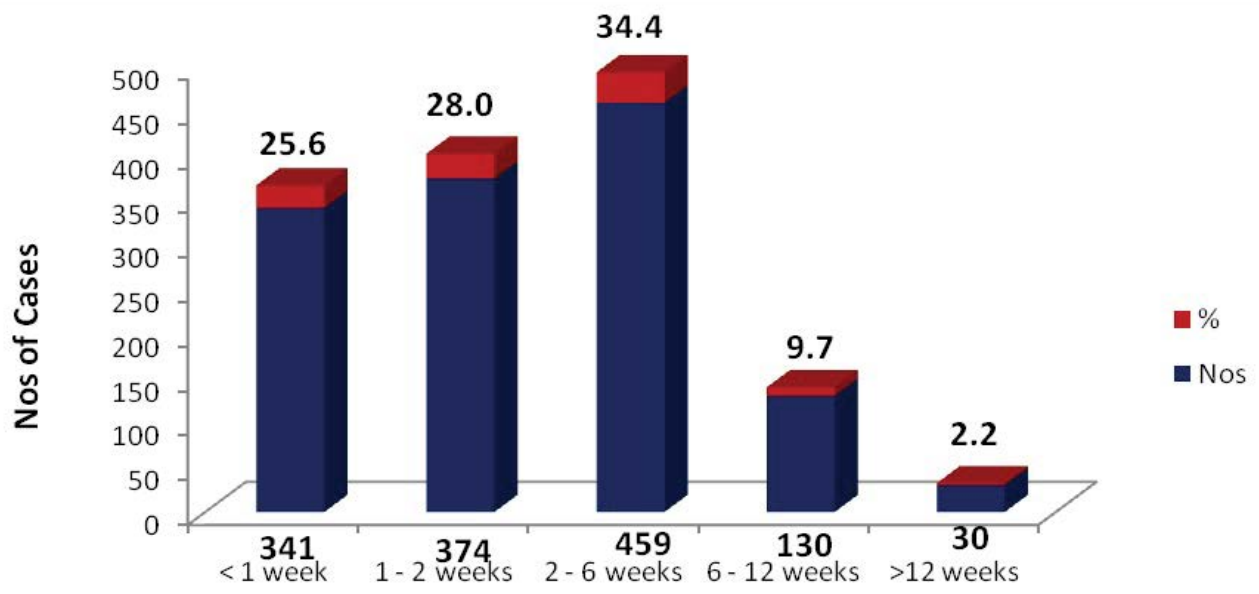

Duration of hospitalisation

Figure 4: Length of Hospitalisation.

Table 3: Localization of fracture \& Laterality of Injury.

\begin{tabular}{|l|l|l|l|l|l|}
\hline Location of fracture & Laterality of Injury & Total & $\%$ & \\
\hline & Left & Right & & & \\
\hline Proximal Femur & 122 & 98 & 220 & 16.5 & \\
\hline Shaft & 380 & 395 & 775 & 58.1 & \\
\hline Distal Femur & 179 & 160 & 339 & 25.4 & \\
\hline Total & 681 & 653 & 1334 & 100.0 & $\chi^{2}=0.588$ \\
& & & & & $P=0.443$ \\
\hline
\end{tabular}

$\left(\chi^{2}=382.724 . \mathbf{P}<0.00001\right)$

Table 4: Definitive treatment given.

\begin{tabular}{|l|l|l|}
\hline Definitive Treatment & Nos & $\%$ \\
\hline Amputation & 5 & 0.4 \\
\hline Casting (POP) & 136 & 10.2 \\
\hline EXFIX & 176 & 13.2 \\
\hline Internal fixation & & \\
\hline \multicolumn{1}{|c|}{ IM nailing } & 629 & 47.2 \\
\hline Plate + Screws & 167 & 12.5 \\
\hline DHS & 26 & 1.9 \\
\hline Screws only & 13 & 1.0 \\
\hline \multicolumn{1}{|c|}{ K-Wires } & 18 & 1.3 \\
\hline Traction & 135 & 10.1 \\
\hline Others & 30 & 2.2 \\
\hline Total & 1334 & 100.0 \\
\hline
\end{tabular}

$\chi^{2}=1742.245, \mathrm{P}<0.00001$.

Other treatments included use of Braces, splints, bed rest.

POP: Plaster of Paris, DHS: Dynamic Hip Screw, EXFIX: External Fixation, ORIF: Open reduction and internal fixation.

admission Figure 4.

Whereas most of the fractures had achieved significant evidence of radiological union as at 12 weeks $(n=$ $1049,78.6 \%), 50$ of the fractures $(3.7 \%)$ had not united as at 24 weeks post definitive treatment including those with extended delayed union. One hundred and sixty-two of the patients were lost to follow up before
Table 5: Duration to Radiological Union of fracture from Definitive Treatment.

\begin{tabular}{|l|l|l|l|}
\hline $\begin{array}{l}\text { Time from Def. } \\
\text { Treatment }\end{array}$ & Frequency & $\sum$ Freq. & $\begin{array}{l}\% \text { Union } \\
\text { rate }\end{array}$ \\
\hline 6 weeks & 159 & 159 & 11.9 \\
\hline 12 weeks & 752 & 911 & 56.4 \\
\hline 18 weeks & 138 & 1049 & 10.3 \\
\hline 24 weeks & 68 & 1117 & 5.1 \\
\hline > 24 weeks & 50 & 1167 & 3.7 \\
\hline Amputation & nil & 1167 & - \\
\hline Loss to follow up & 162 & 1329 & 12.1 \\
\hline Total & 1334 & & 100 \\
\hline
\end{tabular}

$\chi^{2}=1481.717, \mathrm{P}<0.00001$.

Patients whose fractures had not united at 6 months (24weeks) included those with non-union or prolonged delayed.

Table 6: Complications recorded following treatment.

\begin{tabular}{|l|l|l|}
\hline Complication & Nos & $\%$ \\
\hline Infection & 72 & 5.4 \\
\hline Non-union & 20 & 1.5 \\
\hline Malunion & 14 & 1.0 \\
\hline Implant Failure & 16 & 1.2 \\
\hline Others & 19 & 1.4 \\
\hline
\end{tabular}

Other complications included Pulmonary embolism (PE), Deep venous thrombosis (DVT), chronic pain, Nerve injury). 
their fracture union status could be determined Table 5 and Table 6.

Table 7 outlined the relationships between the type of fracture and outcome of treatment. The total infection recorded was 72 (5.4\%) with the highest infection rate recorded among type IIIC open fractures $(n=4,50 \%)$ followed by type III-A open fractures $(n=30$, $27.52 \%$ ) followed closely by type IIIB open fractures ( $\mathrm{n}$ $=7,23.33 \%) \mathrm{P}<0.00001$. Seventeen cases of malunion $(0.01 \%), 25$ cases of non-union $(0.02 \%)$ and 24 cases of implant failure were recorded. The assessment of the functional outcome of treatment using the COST score showed that ( $n=1035,77.6 \%$ ) of the patients had COST Score $70 \%$ and above which indicated significant functional recovery as at 6 months post-treatment. However, there was a significant difference in functional outcome between the closed and type I open fractures and the type III Open fractures $(P=0.01)$.

\section{Discussion}

The result from this study shows that the proportion of fracture of the femur treated at the trauma centre where this study was undertaken $(10.9 \%)$ was comparatively lower when compared to the report from other centres $[8,30]$. The reason for this pattern may not be unconnected to presumably the high patronage of traditional bone setters in the region [31]. Despite not being the most common fracture seen at the hospital, fractured femur remained amongst the most challenging fractures treated in the trauma centre regarding the availability of resources including skill and materials required to operate these fractures.

The result of this study showed a varied spectrum of femur fractures ranging from non-displaced fractures to complex fractures associated with severe comminution and significant soft-tissue injury. All age groups and gender were involved with the highest incidence recorded in males between the age group (21-30) years with the mean age incidence \pm SD being $(28.3 \pm 17.2)$ years $(P<0.0001)$ (Table 1$)$. This pattern had been reported in other series $[2,3]$. The occurrence of fracture in only 62 patients $(4.6 \%)$ out of the lot among persons aged 60 years and above contrary to the pattern in western Europe and North America may be attributable to the lower life expectancy recorded in Nigeria which by 2018 WHO Report stands at 55.2 years and ranked 178 on global ranking [32].

High energy trauma particularly those arising from road traffic crashes was the most frequent cause femur fractures $(n=970\{72.7 \%\})$ particularly in males younger than 50 years $(\{P<0.00001\}$ Table 2$)$. The role of motorcycle traffic crashes as a contributor to femoral crashes in this series ( $n=299,22.4 \%$ ) may be related to the low adherence to road safety measures in the country and use of motorcycle as a means for commercial transportation in the region. Persons who were not previously trained in skills of riding motorcycle often take to commercial motorcycling as a means of livelihood in the face of high unemployment in the region. Ground level falls mainly in the domestic setting was the top most cause of fractured femur seen in this study in the female patients $(23,1.7 \%)$ especially in those older than 60 years. This pattern is similar to those reported in other studies on femoral fracture. The observed pattern may not be unconnected to the higher incidence of osteoporosis of bones after the age of 50 years in the female patients [33].

Of the fractures of the femur seen at the centre, a significant proportion ( $n=1040,78 \%$ ) were closed whereas 294 cases (22\%) were open of various grades $(P<0.00001)$ Figure 1. This pattern is a common finding with femoral fractures as against fractures of tibia because of the rich soft tissue cover of the femur [34]. The highest proportion of the open fractures were of Gustilo Anderson Grade III A ( $n=109,8.2 \%$ ) of transverse or short oblique fracture pattern $(n=1018$, $76.3 \%$ ) involving the shaft of the femur in majority of the cases ( $n=775,58.1 \%$ ) was an indication that most of the fractures resulted from high energy injuries from RTC or gunshot injuries.

Table 7: Relationships between type of fracture and outcome.

\begin{tabular}{|c|c|c|c|c|c|c|c|c|c|c|}
\hline \multirow[t]{2}{*}{ Fracture Type } & \multirow{2}{*}{$\begin{array}{l}\text { No of } \\
\text { cases }\end{array}$} & \multicolumn{9}{|c|}{ Outcome Variable } \\
\hline & & $\begin{array}{l}\text { Infection } \\
\text { rate }\end{array}$ & $\%$ & $\begin{array}{l}\text { Mal- } \\
\text { union }\end{array}$ & $\%$ & $\begin{array}{l}\text { Non- } \\
\text { Union }\end{array}$ & $\%$ & $\begin{array}{l}\text { Implant } \\
\text { failure }\end{array}$ & $\%$ & $\begin{array}{l}\text { COST Score } \geq 70 \% \\
\text { at } 6 \text { months }(\%)\end{array}$ \\
\hline Closed & 1040 & 24 & 2.31 & 10 & 0.01 & 15 & 0.01 & 20 & 0.02 & $838(80.6 \%)$ \\
\hline Open I & 70 & 3 & 4.29 & Nil & & 2 & 0.03 & 3 & 0.04 & $60(85.7 \%)$ \\
\hline Open II & 77 & 4 & 5.18 & 4 & 0.01 & 3 & 0.04 & nil & - & $55(71.4 \%)$ \\
\hline Open IIIA & 109 & 30 & 27.52 & 1 & 0.01 & 3 & 0.03 & nil & - & $64(58.7 \%)$ \\
\hline Open III B & 30 & 7 & 23.33 & nil & - & nil & - & 1 & 0.03 & $15(50 \%)$ \\
\hline Open III C & 8 & 4 & 50 & 2 & 0.02 & 2 & 0.25 & nil & - & $3(62.5 \%)$ \\
\hline Total & 1334 & 72 & 5.40 & 17 & 0.01 & 25 & 0.02 & 24 & 0.02 & $1035(77.6 \%)$ \\
\hline $\begin{array}{l}\chi^{2} \\
P \text { value }\end{array}$ & & $\begin{array}{l}452.243 \\
0.00001\end{array}$ & & & $\begin{array}{l}0 \\
1\end{array}$ & & $\begin{array}{l}3 \\
0.56\end{array}$ & & $\begin{array}{l}3.02 \\
0.54\end{array}$ & $\begin{array}{l}13.277 \\
0.01\end{array}$ \\
\hline
\end{tabular}


The study showed that a significant proportion of the femoral fractures ( $n=1010,75.7 \%$ ) particularly those in adults including the five (5) patients that had amputation were treated surgically $(\{\mathrm{P}<0.00001\}$, Table 4) with the goal of achieving stable, anatomic fixation of the fractures, to allow for mobilization of both the patient and the injured limb as soon as possible which is in keeping with the current recommended standard of care for treatment of femoral fractures [18]. Whereas in children, non-operative methods were the mainstay of treatment in keeping with most recommended practices the adoption of non-operative methods of treatment with either traction or casting (POP) or both combined even in adult patients in this study $(n=271$, 20.3\%) are not in keeping the recommended standard of care presently for the treatment of femoral fractures in adults for reasons of comparatively poorer outcome [17]. Availability of resources and skills influenced the treatment pattern adopted in the centre at any particular time. This reason may explain why some of the fractures in adults were treated by non-operative methods because of the limited availability of skill and resources required for operative treatment of fractures in the centre especially before 2007 . These methods were less employed following the availability of implants and instrumentation for operative treatment of fractures in the centre subsequently.

Of the operative methods, open reduction of the fracture and fixation with plates and screws (plating) was employed on nearly ( $n=167,12.5 \%$ ) of fractures. The concept of plating for fixation of femoral shaft fractures aims at rigid fixation and absolute stability of the fracture $[35,36]$. Less emphasis on respect for the fracture biology resulting from exposure and evacuation of the fracture haematoma with partial and occasionally complete devascularisation of the femoral cortex leading to poor outcome were some of the significant drawbacks of plating. In the centre where this study was undertaken like most other centres in resource-scarce regions, plating sometimes may be the only available option. Besides, plating has the significant advantage of not requiring the full spectrum of specialized operating room equipment and fluoroscopy that are necessary for closed intramedullary nailing [17]. Furthermore, improvements in plate strength, design, and methods of plate insertions have improved outcome with plating. Routine bone grafting of comminuted femoral shaft fractures especially of medial cortical defects with open plate fixation improved outcome with plating and has been recommended [34].

Delay in weight bearing until a significant radiographic union is evident which occasionally ranges from 3 to 5 months remained a major disadvantage of plating when compared with closed reamed intramedullary nailing [17]. Whereas plating was mainly indicated for transverse fractures and short oblique fractures, irrespective of their level on the femoral shaft $[37,38]$, plat- ing for comminuted and long segment fractures were often associated with intraoperative difficulties and poor outcome. Despite its limitations in shaft fractures, plating is the standard of care presently for intraarticular fractures.

Majority of the fractures were treated by locked intramedullary nailing ( $n=629,47.2 \%$ ) which currently is the gold standard for treatment of shaft fractures of long bones particularly the closed method [18,39]. Unfortunately, the required skills, equipment and instrumentation for closed method of fracture fixation are often limited in most centres in the developing countries. Even when the equipment and resources are available, the cost of operating and maintaining these facilities make their use expensive and less affordable to the majority of the patients. Some of the methods devised to overcome some of the intra-operative challenges for locked IM nailing, include the adoption of open reduction approach for most of the fractures before the insertion of IM nails which are then locked with special devices not requiring intraoperative imaging $[39,40]$.

Incidentally, opening of the fracture site for direct reduction of the fracture before insertion of the IM nail as commonly practiced in the study centre compromised the fracture haematoma with the potential for increased risk of postoperative infections which was one of the drawbacks of plating. However, the observed infection rate, particularly in the closed fracture subgroup, treated operatively $(2.3 \%)$ in this study was well within the acceptable infection rates by most orthopaedic trauma guidelines $[28,41]$.

External fixation for the treatment of the femoral shaft in this study was mainly for open fractures $(n=$ $176,13.2 \%)$, particularly for grade III open fractures. The adoption of external fixation in the treatment of some closed fractures in this study when the resources for internal fixation were unavailable in the centre is worth noting. External fixation for the treatment of femoral shaft fractures is not a standard practice except for open fractures with associated complex soft tissue injuries. External fixation for the treatment of closed shaft fractures of long bones including the femur has been reported especially from Eastern Europe and some developing countries [42]. A comparative study between external fixation and interlocking intramedullary fixation for closed fractures of the femoral shaft by Murphy and colleagues [43] showed clear superior clinical results with the intramedullary technique; however, the severity of injuries between the two treatment groups was not identical. Murphy and colleagues, therefore, concluded that external fixation could not be indicated in the routine treatment of closed fractures of the femoral shaft [43]. The adoption of external fixation as initial fracture stabilization in multiply injured patients as part of "Damage control orthopaedics" was minimal 
as the concept was evolving and not routinely practiced in the region as at the time covered by this study.

Evaluation of the outcome of fractures in this study showed an infection rate of $5.4 \%(n=72)$ is comparatively lower than those reported from other centres in the region $[44,45]$ but in keeping with acceptable infection rates following treatment of fractures [28]. When the infection rates were disaggregated for various types of fracture, it showed that highest rates were recorded among the higher grades of open fracture i.e. grades III A, B, C ( $n=30 ; 27.52 \%, n=7 ; 23.33 \%, n=4 ; 50 \%)$ respectively which was significantly higher than those of closed and open type I fractures $(\{\mathrm{P}<0.00001\}$ Table 7$)$. This finding was similar to the earlier report by Gustilo and Anderson [28].

The observed mal-union rates ( $n=17 ; 0.01 \%)$, nonunion rates $(n=25,0.02 \%)$, implant failure rates $(n=$ $24,0.02 \%)$ were not statistically significant between the various types of fractures $(\{P>0.05 \%\}$ Table 7$)$. The functional outcome as assessed by COST Score which showed 1035 of the patients (77.6\%) having scores of $70 \%$ and above at six months after treatment was indicative of fairly good outcome with results of all outcome variables assessed comparable with those recorded in other studies $[16,28]$. This observation confirms that operative methods can safely be adopted for treatment of fractures of the femur in adults in the region with acceptable outcomes. The observed outcomes may be attributable to the strict adherence to established protocols and guidelines borrowed from other better-developed systems.

\section{Conclusion}

Fracture of the femur is a relatively common fracture treated at the centre. Femoral fracture has diverse pattern of presentation in its aetiology, treatment given and outcome in the centre. Road traffic crashes remain a significant contributor to femoral fractures in the region especially in the active young males as such approach to prevention of fractures of the femur will include improved road safety issues in the region. Treatment of such fracture can be challenging particularly when the fracture is complicated with extensive soft tissue injuries especially in region with limited available resources. Whatever treatment options that are available, application of good clinical skills and appropriate adherence to established treatment guidelines produces acceptable results even in the face of limited resources.

\section{Ethics Approval}

Study was approved by the Research and Ethical Review Committee of International Centre for Advanced Medical Care and Development (ICAMCAD) who are the developers of the registry.

\section{Consent}

Not applicable.

\section{Availability of Data and Material}

The data that support the findings of this study are available from the authority of International Centre for Advanced Medical Care and Development (ICAMCAD), but restrictions apply to the availability of these data, which were used under license for the current study, and so are not publicly available. Data are however available from the authors upon reasonable request and with permission of the authority of International Centre for Advanced Medical Care and Development.

\section{Acknowledgements}

We acknowledge the Board and Management of International Centre for Advanced Medical Care and Development for allowing access to the data from their trauma registry.

\section{Competing Interests}

Authors have declared that no competing interests exist.

\section{Author's Contribution}

Both authors contributed in the design, analysis and interpretation and preparation the manuscript.

\section{References}

1. Whittle AP (2008) Fractures of the lower extremity. In: Canale ST, Beatty JH, Campbell's Operative Orthopedics. $\left(11^{\text {th }}\right.$ edn), Mosby, St. Louis, 3190.

2. Moore KL, Agur AM (2009) Clinically Oriented Anatomy, ( $6^{\text {th }}$ edn), Williams \& Wilkins, Baltimore.

3. Nork SM (2010) Fractures of the shaft of the femur. In: Bucholz RW, Heckman JD, Court-Brown CM, et al. Rockwood and Green's Fractures in Adults. ( $7^{\text {th }}$ edn), Lippincott, Williams \& Wilkins, Philadelphia, 1656.

4. Hedlund R, Lindgren $U$ (2009) Epidemiology of diaphyseal femoral fracture. Acta Orthop Scand 57: 423-427.

5. Baron JA, Karagas M, Barrett J, Kniffin W, Malenka D, et al. (1996) Basic epidemiology of fractures of the upper and lower limb among Americans over 65 years of age. Epidemiology 7: 612-617.

6. Arneson TJ, Melton III LJ, Lewallen DG, O’Fallon WM (1988) Epidemiology of diaphyseal and distal femoral fractures in Rochester, Minnesota, 1965-1984. Clin Orthop Relat Res 234: 188-194.

7. Bengnér U, Ekbom T, Johnell O, Nilsson BE (1994) Incidence of femoral and tibial shaft fractures. Epidemiology 1950-1983 in Malmö, Sweden. Acta Orthop Scand 61: 251254.

8. Anyaehie UE, Ejimofor OC, Akpuaka FC, Nwadinigwe CU (2015) Pattern of femoral fractures and associated injuries in a Nigerian tertiary trauma centre. Niger J Clin Pract 18: 462-466.

9. Bucholz RW, Jones A (1991) Fractures of the shaft of the femur. J Bone Joint Surg Am 73: 1561. 
10. Adnan RM, Zia MI, Amin J, Khan R, Ahmed S, et al. (2012) Frequency of femoral fractures; comparison in patients less than and more than 40 years of age. Professional Med $\mathrm{J}$ 19: 11-14.

11. Ibeanusi SEB, Harcourt SL (2017) The Pattern and Outcome of Severe Trauma Using the Trauma and Injury Severity Score (TRISS) Methodology in a Dedicated Trauma Centre in Nigeria. Br J Med Med Res 21: 1-9.

12. Solagberu BA, Adekanye AO, Ofoegbu CP, Udoffa US, Abdur-Rahman LO, et al. (2003) Epidemiology of trauma deaths. West Afr J Med 2: 177-181.

13. Keel M, Trentz O (2005) Pathophysiology of polytrauma. Injury 36: 691-709.

14. Obaidur R, Adnan RM, Khan R, Rahman F, Zia MI, et al. (2013) Pattern of Femoral Fractures. Journal of Rawalpindi Medical College (JRMC) 17: 42-44.

15. Marsh D (1998) Concepts of fracture union, delayed union, and non-union. Clin Orthop Relat Res (355): S22-S30.

16. Wu CC (2006) Treatment of Long-Bone Fractures, Malunions, and Non-unions: Experience at Chang Gung Memorial Hospital, Taoyuan, Taiwan. Chang Gung Med J 29: 347-357.

17. Bucholz R, Brumback R (1996) Fractures of the shaft of the femur. In: Rockwood C, Green D, Bucholz R et al. Rockwood and Green's Fractures in Adults. ( $4^{\text {th }}$ edn), Lippincott-Raven, Philadelphia, USA, 1827-1918.

18. Reynders PA, Broos PL (2000) Healing of closed femoral fractures treated with the $A O$ unreamed femoral nail. $A$ comparative study with the AO reamed femoral nail. Injury 31: $367-371$

19. Olaorodun DA, Oladiran IO, Adeniran A (2001) Complications of fracture treatment by Traditional Bonesetters in Southwest Nigeria. Family Practice 18: 635-637.

20. Dufour D, Kromann Jensen S, Owen Smith M, Salmela J, Stening GF, et al. (1988) Surgery of the victims of war. International Committee of the Red Cross, Geneva.

21. Coupland RM (1991) The Red Cross Wound Classification. International Committee of the Red Cross, Geneva, 15.

22. Riska EB, Myllynen $P$ (1982) Fat embolism in patients with multiple injuries. J Trauma 22: 891-894.

23. Charash WE, Fabian TC, Croce MA (1994) Delayed surgical fixation of femur fractures is a risk factor for pulmonary failure independent of thoracic trauma. J Trauma 37: 667-672.

24. Harwood PJ, Giannoudis PV, van Griensven M, Krettek C, Pape HC (2005) Alterations in the systemic inflammatory response after early total care and damage control procedures for femoral shaft fracture in severely injured patients. J Trauma 58: 446-454.

25. Hildebrand F, Giannoudis P, van Griensven M, Chawda M, Probst C, et al. (2005) Secondary effects of femoral instrumentation on pulmonary physiology in a standardised sheep model: what is the effect of lung contusion and reaming? Injury 36 : 544-555.

26. Pape HC, Giannoudis P, Krettek C (2002) The timing of fracture treatment in polytrauma patients: relevance of damage control orthopaedic surgery. Am J Surg 183: 622-629.

27. Iliopoulos E, Agarwal S, Khaleel A (2017) Chertsey Outcome Score for Trauma: Development and validation of a new unifying patient reported outcome measure for orthopaedic trauma. Chin J Traumatol 20: 329-332.

28. Gustilo RB, Anderson JT (1976) Prevention of infection in the treatment of one thousand and twenty-five open fractures of long bones: retrospective and prospective analyses. J Bone Joint Surg Am 58: 453-458.

29. Altemeier WA, Burke JF, Puitt BA, Sandusky WR (1984) Manual on control of infection in surgical patients. $\left(2^{\text {nd }} e d n\right)$, Philadelphia, USA, 29.

30. Ogbemudia AO, Umebese PFA (2006) Implant failure in osteosynthesis of fractures of long bones. Journal of Biomedical Sciences 5: 75-78.

31. Ibeanusi SE, Diamond TE (2018) Traffic related injuries from a trauma registry: Pattern and outcome. Niger $\mathrm{J}$ Orthop Trauma 17: 22-28.

32. World Health Organization (2019) World Health Rankings 2018.

33. Rüedi TP, Lüscher JN (1979) Results after internal fixation of comminuted fractures of the femoral shaft with DC plates. Clin Orthop Relat Res 138: 74-76.

34. Platzer W. Locomotor system (2009) Color Atlas of Human Anatomy. (6 $6^{\text {th }}$ edn), Thieme Medical Publishers, Stuttgart, 2009.

35. Rüedi TP, Lüscher JN (1979) Results after internal fixation of comminuted fractures of the femoral shaft with DC plates. Clin Orthop Relat Res 138: 74-76.

36. Cheng JC, Tse PY, Chow YY (1985) The place of the dynamic compression plate in femoral shaft fractures. Injury 16: 529-534.

37. Böhler L (1957) The treatment of fractures. Grune \& Stratton, New York London.

38. Dencker HM (1963) Fractures of the shaft of the femur. A clinical study based on 1003 fractures treated in Swedish hospitals during the three-year period 1952 to 1954 . Thesis, 1-135. University of Gothenburg, Gothenburg.

39. IC Ikem, O Esan, EA Orimolade, AA Adetiloye, AM Toluse (2011) External jig in the placement of distal interlocking screws. Nigerian J Orthop Trauma 10: 28-31.

40. Ibeanusi SE (2018) Locked Intramedullary Nailing of Fractures. Experience from a Trauma Centre in Nigeria: A Prospective Observational Study. Asian J Orthop Surg 1: 1-10.

41. Metsemakers WJ, Morgenstern M, McNally MA, Moriarty TF, McFadyen I, et al. (2018) Fracture-related infection: A consensus on definition from an international expert group. Injury 49: 505-510.

42. Zlowodzki M, Prakash JS, Aggarwal NK (2007) External fixation of complex femoral shaft fractures. Int Orthop 31: 409-413.

43. Murphy CP, D'Ambrosia RD, Dabezies EJ, Acker JH, Shoji $\mathrm{H}$, et al. (1988) Complex femur fractures: treatment with the Wagner external fixation device or the Grosse-Kempf interlocking nail. J Trauma 28: 1553-1561.

44. Wariboko TC, Obalum DC, Ibeanusi SE, Alonge TO, Ogunlade SO, et al. (2017) The Trend of Wound Microbial Characteristics in Open Fractures at the University College Hospital, Ibadan. Niger J Orthop Trauma 16: 18-28.

45. Ifesanya AO, Alonge TO (2012) Operative stabilization of open long bone fractures: A tropical tertiary hospital experience. Niger Med J 53: 16-20. 